\title{
Endoscopic needle knife fistulotomy technique for ileal pouch-to-pouch fistula
}

A 19-year-old woman with refractory pan-ulcerative colitis, diagnosed in 2004, underwent a total proctocolectomy in 2006, followed by a two-stage ileoanal pull-through procedure. Severe pouchitis led to a two-stage J-pouch reconstruction in 2012. In June 2014, magnetic resonance enterography showed a pre-sacral abscess, which was drained percutaneously. We performed a pouchoscopy with a GIFH190 endoscope (Olympus, Tokyo, Japan) in an outpatient setting. After the administration of conscious sedation, inspection of the pouch showed a defect draining purulent material at the distal pouch along the anastomotic line ( $\nabla$ Fig. 1). Suspecting an anastomotic sinus or fistulous track, we used a 0.035-inch guidewire with a flexible tip (Boston Scientific, Natick, Massachusetts, USA) to investigate ( $\bullet$ Fig. 2 and - Fig.3). A 3-cm-long pouch-to-pouch fistula was detected. A $1.8-\mathrm{mm}$ needle knife (Boston Scientific) was used with electrocautery to cut across the fistulous track wall-now a septum separating the fistula from the pouch ( Video 1 ). Three endoscopic hemoclips were placed along the opened fistula track to prevent re-formation of the fistula. Complete fistulotomy was achieved, and surgical intervention for abscess drainage was avoided. The procedure took 25 minutes and was uneventful.

\section{Video 1}

Endoscopic use of the needle knife to open the pouch-to-pouch fistula.
Endoscopy_UCTN_Code_TTT_1AQ_2AF

\section{Competing interests: None}

\section{Vivian Chidi ${ }^{1}$, Bo Shen ${ }^{2}$}

${ }^{1}$ Division of Gastroenterology, Hepatology and Nutrition, Vanderbilt University Medical Center, Nashville, Tennessee, USA

2 Department of Gastroenterology and Hepatology, Cleveland Clinic Foundation, Cleveland, Ohio, USA

\section{Bibliography}

DOI http://dx.doi.org/

$10.1055 / \mathrm{s}-0034-1391867$

Endoscopy 2015; 47: E261

(c) Georg Thieme Verlag KC

Stuttgart · New York

ISSN 0013-726X

\section{Corresponding author}

\section{Bo Shen, MD}

Digestive Disease Institute

Cleveland Clinic

9500 Euclid Avenue

Cleveland, $\mathrm{OH} 44195$

USA

Fax: +1-216-444-6305

shenb@ccf.org

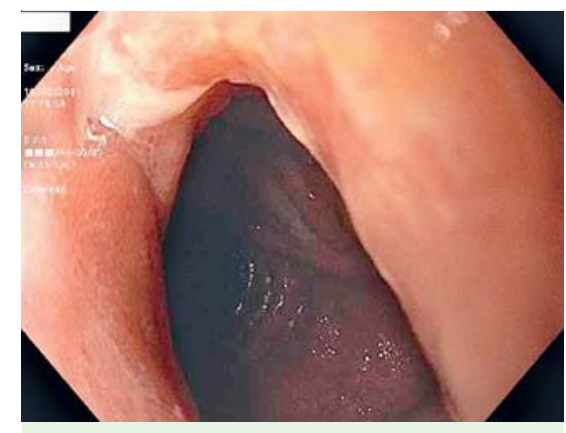

Fig. 1 Purulent material draining from the fistula opening at the anastomotic line of the ileal pouch in a 19-year-old patient with a pre-sacral abscess.

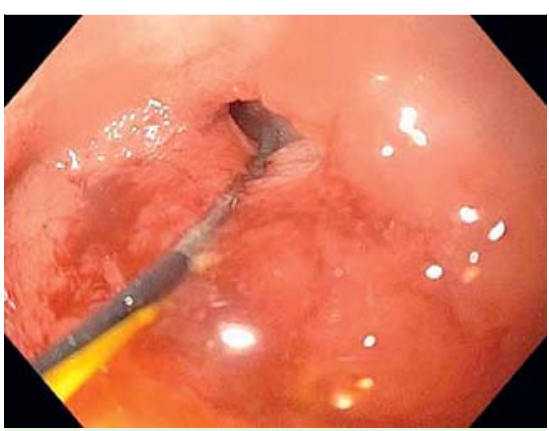

Fig.2 Insertion of the probe into the fistula opening.

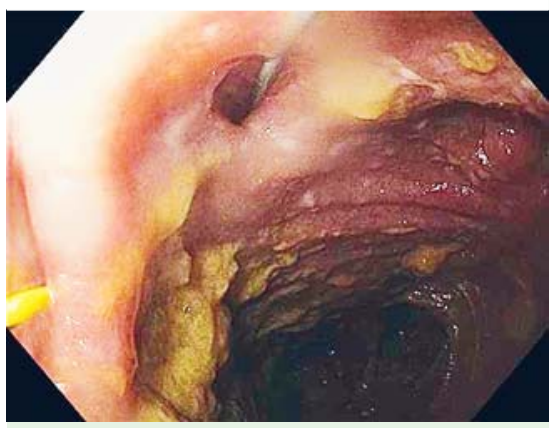

Fig. 3 Use of the guidewire to investigate the fistula track. 